\title{
Conomics
}

The Open-Access, Open-Assessment E-Journal

Discussion Paper

Nr. 2009-30 | June 23, 2009 | http://www.economics-ejournal.org/economics/discussionpapers/2009-30

\section{Diversity of Science Linkages and Innovation Performance: Some Empirical Evidence from Flemish Firms}

\author{
Bruno Cassiman \\ IESE Business School, K.U.Leuven and CEPR \\ Reinhilde Veugelers \\ K. U. Leuven, Bruegel and CEPR \\ Pluvia Zuniga \\ OECD
}

\begin{abstract}
This paper examines the diversity of the types of links of firms to science and their effect on innovation performance for a sample of Belgian firms. While at the industry level links to science are highly related to the R\&D intensity of the sector, we show that there exists considerable heterogeneity in the type of links to science at the firm level. Overall, firms with a science link enjoy superior innovation performance, in particular with respect to innovations that are new to the market. At the invention level, our findings confirm that patents from firms engaged in science are more frequently cited and have a broader technological and geographical impact, but we show that it is crucial to distinguish between direct science links at the invention level and indirect science links at the firm level to encounter these distinct positive effects of science links.
\end{abstract}

Paper submitted to the special issue

The Knowledge-Based Society: Transition, Geography, and Competition Policy

JEL: O32, O34, L13

Keywords: Innovation; cooperation; patents; forward citation; science; industrial innovation

\section{Correspondence}

Bruno Cassiman, IESE Business School, Avenida Pearson 21, 08034 Barcelona, Spain; e-mail: bcassiman@iese.edu

This paper is based on a document prepared for the OECD Blue Sky II meeting in Ottawa, Canada. Bruno Cassiman is a fellow of the SPSP Research Center at IESE Business School and acknowledges financial support from the Spanish Ministery of Education (SEJ200611833/ECON). Reinhilde Veugelers is a co-promotor of ECOOM and acknowledges financial support from KULeuven (OT/07/011), the FWO (G.0523.08) and the PAI (P6/09). 


\section{Introduction}

An important and recurrent concern in economics has been to understand to what extent science influences technological progress. This literature has shown that knowledge flows from universities and public research centres make a substantial contribution to industrial innovation and, consequently, to public welfare. ${ }^{1}$

More recent research suggests that the links to basic research by industrial firms have dramatically increased in the last decade. There is evidence of rising university spin-offs (Jensen and Thursby, 2001; Thursby and Thursby, 2002), university-industry collaboration (Liebeskind et al, 1996; Darby and Zucker; 2001; Zucker et al, 2001; 2002), mobility of university researchers (Kim et al, 2005), science-linkage in private patents (Narin et al, 1997; Hicks et al, 2001), and so forth. Narin et al (1997) report a threefold increase in the number of academic citations in industrial patents in the United States through the mid 1990s. ${ }^{2}$ These patterns suggest an increased opportunity for innovation offered by linking to science and scientific institutions.

In spite of this growing evidence about firms connecting to science, our understanding at the firm level about how knowledge transfers occur through these links and how they affect industrial innovation remains unclear. The main incentive for enterprises to engage in industryscience links (ISL) is to access scientific know how and knowledge. For private organizations to create and maintain such links to science, ultimately, this knowledge should increase the productivity of own internal research (Evenson and Kislev, 1976; Gambardella, 1992;

\footnotetext{
${ }^{1}$ The importance of academic research for industrial innovation has also been corroborated in studies based on industrial survey and patent statistics (Mansfield, 1991, 1995; Cohen, Nelson and Walsh, 2002).

${ }^{2}$ Narin, Hamilton, Olivastro (1997), Branstetter (2004), and Van Looy et al (2004), have all confirmed an increasing citation to academic publications in patents
} 
Cassiman et al., 2001). The role and importance of science will be affected by industry factors, but also by firm and invention level factors.

In this article, we shed some light on the debate on the importance of ISL by looking at the “diversity” of linkages to science employed by Flemish firms and their relationship to innovative performance. Combining patent, publication and innovation survey information for these firms, a wide variety of industry science link indicators can be considered: i) cooperative R\&D agreements with public research centers and universities, ii) use of public information sources - universities, public research centers, conferences, meeting and publications - to innovate, iii) citation to scientific literature in patents of the firm, and, iv) involvement in scientific publications by the firm.

A first contribution of the paper is to show the diversity in ISL being used by firms, suggesting the need to look beyond a single "silver-bullet" industry-science link, to include the full portfolio of industry science links. A second contribution of this paper consists in evaluating whether these different types of ISL enhance industrial innovation and economic performance of the firms using ISL. Two types of analysis are presented. First, we relate linkages to science to the different indicators of innovation and economic performance at the firm level (with performance measured as turnover due to innovation and turnover due to market introduction as reported in the CIS 1998-2000 data). Second, we delve further into the micro-level connections between science and innovation performance, focusing on the invention (i.c. patent) level. For this we restrict the sample to patenting firms and compare the differences in patent quality (forward citation) between patents with and without science linkages. We also return to the firm level, by comparing the quality of patents (forward citations) of firms with science linkages vis-à-vis patents of other firms. We thus provide an evaluation of the effectiveness of 
the science-linkages to enhance technological performance by looking at the quality of private inventions.

The paper is organized as follows. Section I presents a summary of the literature and reviews previous empirical work on the value of science for industrial innovation. While our contribution is intended to be rather descriptive, the review does lead to the formulation of our main hypotheses. Section II describes our data and the methodology. Basic descriptives are presented on the frequency of ISL, and the adoption of ISL by firms across various types of industries. Section III evaluates the relationship between ISL and firms' innovation performance. The final section concludes and identifies some preliminary policy implications based on our research.

\section{The value of Science}

The value of science for innovation and growth has been demonstrated using a diverse set of methodologies. In large sample research Griliches (1979) and Adams (1990) have shown the important contribution of basic research (e.g. public research expenditures and scientific publications) to economic growth. Complementary research based on surveys has provided an alternative estimation of the contribution of basic research for industrial innovation and economic performance. In a survey of 76 U.S. firms in seven industries, Mansfield (1991) found that $11 \%$ of new product innovations and $9 \%$ of process innovations would not have been developed (without substantial delay) in the absence of recent academic research; these innovations represented respectively 3\% and 1\% of sales. Both the 1983 Yale Survey and the 1994 Carnegie Mellon Survey of R\&D have also shown the relevance of university research for industrial innovation and provide some insight as to the importance of different channels (Cohen et al, 2002). According to the 1994 Carnegie Mellon Survey, American firms 
considered publishing by universities and patenting amongst the most important sources of knowledge for the innovation process. ${ }^{3} \quad$ In a survey of Europe's largest industrial firms, Arundal and Geuna (2004) find that public science is amongst the most important sources of technical knowledge for the innovative activities. Evidence from the European community innovation surveys (CIS) indicates that $31 \%$ of firms that develop products or processes that are new to the market is an important source of information for the innovation process, compared to a mere $4 \%$ of all innovating firms who find these information sources important in general (EC-DGECFIN, 2000). Therefore, it seems that science is more important as a source of knowledge for innovation when innovations new to the market are developed.

The management literature has tried to open the firm's black box on how science linkages can improve the productivity of firm's internal research. Different mechanisms have been associated with this beneficial effect of science on innovation performance of firms. First, investment in science generates absorptive capacity and a better understanding of scientific research. As a result, the firm more easily identifies and integrates external information, enhancing the productivity of internal research (Cohen and Levinthal, 1989 and 1990; Arora and Gambardella, 1990) Second, Cockburn and Henderson (1998) argue that returns to science are exploited through economies of scope across different product lines. They trace these effects across therapeutical classes within the same pharmaceutical company. A third mechanism advanced by Fleming and Sorenson (2004) is that science serves as a map of the technological landscape and directs private research towards the most promising technological venues avoiding thereby wasteful experimentation. ${ }^{4}$ Finally, Stern (1999) shows that the

\footnotetext{
${ }^{3}$ The results indicate that the key channels through which university research impacts industrial R\&D include published papers and reports, public conferences and meetings, informal information exchange, and consulting. ${ }^{4}$ According to Fleming and Sorenson (2004), scientific knowledge differs from that derived through 'local' search within the firm -which is closely related to firms' prior research activities-, namely because the scientific endeavour attempts to generate and test theories and fundamental ideas, whereas local search is focused on finding new technological solutions within a predetermined pool of knowledge.
} 
adoption of pro-publication incentives for employees helps firms attract high quality academic researchers whose economic value might frequently be higher than their actual remuneration. Researchers looking for academic reputation, may want to pursue research projects leading to publications and are, therefore, likely to accept lower salaries in exchange of permission to keep up with scientific research. These researchers provide value along two dimensions: they not only generate important labor costs reductions and consequently higher productivity of internal research, but they also constitute a bridge with the scientific or academic world.

A growing literature has tried to empirically assess the impact of ISLs on firm performance (e.g. Audretsch and Stephan, 1996; Zucker et al 1998; Cockburn and Henderson, 1998). Using university collaboration as an ISL, these papers seem to support the hypothesis that these links boast internal R\&D investment (Adams et al, 2000), innovation productivity and sales (Belderbos et al, 2005). ${ }^{5}$ While they provide little explanation about the process through which science affects private innovation, the studies have found that science involvement and ties with academic star scientists lead to more patented technology (Henderson and Cockburn, 1996; Zucker et al, 2002; Cockburn and Henderson, 1998); more "important" patents: i.e. international patents (Henderson and Cockburn, 1996); and higher average of quality adjusted patenting at the firm level (Zucker and Darby, 2001; Zucker et al, 2002).

The work of Cockburn and Henderson (1998) has shown that absorptive capacity is also affected by the closeness of the firm to scientific communities (Cohen and Levinthal, 1989; Kamien and Zang, 2000). Using data on co-authorship of scientific papers for a sample of pharmaceutical firms, they show that firms connected to science show a higher performance in

\footnotetext{
${ }^{5}$ For instance, Lööf and Broström, (2004) have found complementarities between internal R\&D and collaboration with universities: the average R\&D firm that cooperates on innovation with universities spend more money on R\&D and has a larger propensity to apply for patents compared to an almost identical R\&D firm which has no such collaboration.
} 
drug discovery and that this connectedness is closely related to the number of star scientists employed by the firm. ${ }^{6}$ Zucker et al (1998) and Darby and Zucker (2001) found that the location of top star scientists predicts firm entry into biotechnology (by new and existing firms) both in the United States and Japan. Darby and Zucker (2005) find similar evidence that firms enter nanotechnology where and when scientists are publishing breakthrough academic articles. ${ }^{7}$ In addition, collaborations between particular university star scientists and firms had a large positive impact on firm research productivity, increasing the average firm's biotech patents by 34 percent, products in development by 27 percent, and products on the market by 8 percent (Darby and Zucker, 2001).

In spite of such apparent benefits, the adoption of science by private firms remains limited and the benefits of science links seem hard to trace at the firm level as evidenced by different studies. Due to the highly specific nature of the know-how involved, only a select set of firms within specific industries tend to show strong interest in the scientific know-how offered by universities or other research institutes. Not surprisingly, in a survey based study on 38 Advanced Technology Projects, Hall et al (2001) found that projects with university involvement tend to develop new knowledge and therefore experience more difficulty and delay but also are more likely not to be aborted prematurely. ${ }^{8}$ As a result, $R \& D$ managers often resent dealing with such joint projects (see Cassiman et al. 2009). Furthermore, linking with science is not costless as it requires the adoption of new organizational practices and the

\footnotetext{
${ }^{6}$ Differences in the effectiveness with which a firm is accessing the upstream pool of knowledge correspond to differences in the research productivity of firms of as much as $30 \%$.

${ }^{7}$ Furthermore, they report a similar pattern previously reported in biotech: breakthroughs in nanoscale science and engineering appear frequently to be transferred to industrial application with the active participation of discovering academic scientists.

${ }^{8}$ In a sample of 62 U.S. university licensing officers, Jensen and Thursby (2001) find that over $75 \%$ of the inventions licensed by these universities were in a very early, or embryonic stage. Further, $71 \%$ of the inventions licensed required cooperation between the professor and the licensing firm in order to commercialize a product successfully. Relying on the CIS for Belgium, Veugelers and Cassiman (2005), find that cooperation with universities is formed whenever risk is not an important obstacle to innovation.
} 
recruitment of qualified scientists (Gambardella, 1994; Cockburn et al, 1999). Given these obstacles, firms will carefully assess the expected costs and benefits from developing ISL.

While most studies have focused on a particular type of ISL - often in pharmaceuticals, biotechnology or nanotechnology, we believe that a variety of types of ISL are viable conditional on the underlying industry, firm and technological conditions. Nevertheless, firms interested in ISL are expected to access science through different complementary modes as the marginal cost of investing in additional modes of linking with science is lower once the cost of organizing accordingly has been sunk.

In what follows, we will first document the diversity of ISL that firms can develop. As argued, we expect a certain degree of complementarity between these different ISL measures. For example, we expect that firms actively engaged in publishing their research are likely to have collaborative agreements with universities and find publicly available knowledge important for their innovation process. Second, we will examine the relative performance of these different ISL. While the overall performance of ISL is expected to be positive, little is actually known about the relative performance of different types of ISL. Furthermore, we will delve into the firm and examine the effect of ISL at a more disaggregated level: the invention (i.c. patent) level. We expect that at the invention level ISL would also positively impact performance, affecting the quality of inventions, as proxied by the citations received by these patents. Previous empirical research has shown that patents of universities are broader in scope and cited more frequently than private patents because they rely on more fundamental knowledge suggesting that public science is an important input for the innovative activities of firms (e.g. Jaffe et al, 1993; Henderson et al, 1998; Narin et al., 1997). Yet, there is little evidence about 
the effectiveness of science to explain the quality of private patents (see Cassiman et al. (2008)

for a more elaborate analysis at the invention level).

\section{The diversity of Linkages to Science}

A first objective of our analysis is to assess the heterogeneity in industry science links used by firms. To this end, we use data on firms' research strategies from the Third Community Innovation Survey (1998-2000) conducted in Belgium in 2000. ${ }^{9}$ A mail survey was sent out to a representative sample of manufacturing firms and the intended respondent was the CEO or the $R \& D$ manager of the establishment. A total of 1471 responses were obtained from the 2726 surveys sent, resulting in a response rate of $54 \%$. In this paper, we limit our sample to the 842 manufacturing firms that are engaged in innovation activities. ${ }^{10}$ We complemented the survey results with patent and publication data of the firms. This allowed constructing the following measures of ISL:

i) A dummy variable (0/1) indicating whether the firm had at least one cooperative agreement in $R \& D$ with universities or public research centers.

ii) A dummy variable (0/1) indicating whether the firm considers public information a very important source for innovation. Firms scored the importance of public information - (i) information from universities, (ii) public research institutions, or (iii) conferences, meetings or publications - on a scale from “0” (unimportant) to " 3 ” (very important). Firms scoring “3” (very important) on one of these information sources are coded " 1 " in our measure of the importance of public information for the innovation

\footnotetext{
${ }^{9}$ Since 1994 the European Community organizes every 4 years the EU wide "Community Innovation Survey" (CIS) on innovation practices by firms. The survey is organized by Eurostat, the statistical agency of the EU, but every member state is responsible for organizing the actual survey in its territory. The survey provides quantitative and qualitative information about the firms’ innovation activities. Questions range from internal and external R\&D activities, R\&D cooperation partners, sources of information of the innovation process, objectives of the innovation process, to questions about the effectiveness of protection measures of knowledge, etc. The survey has been widely used in recent years to examine innovation practices of firms.

${ }^{10}$ These firms had successfully introduced new products or processes from 1998 to 2000, or, claimed to be actively engaged in innovation activities during those years and projects failed or did not produce any outcomes yet.
} 
process.

iii) A dummy variable (0/1) indicating whether the firm is simultaneously engaged in a cooperative agreement in $R \& D$ with universities or public research centers, and, considers public information a very important source for innovation (effectively this measure is an interaction between the two previous measures).

iv) A dummy variable (0/1) indicating whether the firm has been engaged in publication activity. The measure takes the value of " 1 " if the firm published at least one scientific article between 1990 and 1995, predating the survey years and any patents of the firm (see below). Data on publications is collected from the ISI-Web of Knowledge database using the affiliation of the authors. A publication is considered scientific if it is found in the ISI Web of Knowledge and one of the authors is affiliated to the firm.

v) A dummy variable (0/1) indicating whether the firm has patents that contain references to scientific papers. These references are termed scientific non-patent references $(\mathrm{NPR})^{11}$. An NPR is considered scientific if it is found in the ISI-Web of Science. We collected all the patents of our CIS-3 firms in the European patent database (EPO ESPACE-B database) with grant dates between 1995 and 2001. These patents fall within the same time frame as the CIS survey. A total of 1186 patents were granted to 79 firms reported in CIS-3.

Tables 1 and 2 report the distribution of firms across the different measures of ISL and across industries. The first finding that emerges from these tables is the high number of firms without any ISL. About $75 \%$ of innovating firms do not have any linkage to science through

\footnotetext{
11 Some researchers consider (e.g. Jaffe et al., 1993) patent and non patent citations as a "noisy signal” of knowledge flows, with examiners adding much of the noise. As patent and non patent references are issued from the examiner revision of the prior art in the European Patent Office, citations may rarely reflect or coincide with the science used by inventors. Care should therefore be exercised when interpreting the citation results as measures of direct knowledge flows. Nevertheless, some evidence exists that scientific NPRs are more likely inventor given compared to regular patent references (see Alcacer and Gittelman, 2006).
} 
cooperative R\&D agreements nor find public information very important for their innovation process. Not surprisingly, Table 2 shows that the low R\&D intensive industries have the highest percentage of firms not having any connection to science (82\%) while the opposite is true in the high $R \& D$ intensive industries, confirming the importance of technology and industry characteristics driving ISL. ${ }^{12}$ Within the high R\&D intensive industries, $25 \%$ of firms are engaged into cooperation with public institutions, 33\% consider the use of public information as very important for innovation; while $16 \%$ declare to be engaged in both strategies. These results are related to the underlying industry effects as seen in Table 1 where Electronics and Medical and precision instruments followed by Chemicals (including pharmaceuticals) score high on all types of ISL. Some interesting industry variation in the relative use of ISL emerges across industries from Table 1 though. Firms in Wood, printing and publishing industries or in Glass/Ceramics find public information sources relatively more important compared to engaging in cooperative agreements. Contrarily, firms in the Medical and precision instruments, Electronics or Vehicles business rely more on cooperation than on public information for their connections to science. Only very few firms report citations to the scientific literature in their patents. They represent less than $3 \%$ of the population of manufacturing firms in CIS casting some doubt on the relevance of such indicators for understanding links to science in the population of firms. If we consider only the population of patenting firms, 24\% (19 firms out of 79) of these firms report an ISL in their patents.

\footnotetext{
12 We follow the criteria used by the OECD (OECD Science and Technology, 2001). Manufacturing industries are classified in three different categories of technological intensity: high technology, medium-technology industries (grouping medium-high technology and medium-low technology) and low technology. High-technology industries include (ISIC. 3): Aerospace, Office \& computing equipment; Drugs \& medicines, Radio, TV \& communication equipment. Medium Technology groups the two classes distinguished by OECD: Medium-high-technology industries (Scientific instruments, Motor vehicles, Electrical machines excl. Communication equipment, Chemicals excl. drugs, Other transport, and Non-electrical machinery) and Medium-low-technology industries (Rubber \& plastic products, Shipbuilding \& repairing, Other manufacturing, Non-ferrous metals, Non-metallic mineral products, Metal products, Petroleum refineries \& products, Ferrous metals). Low-technology industries are: Paper, products \& printing; Textiles, apparel \& leather; Food, beverages \& tobacco and Wood industries.
} 
Figure 1 attempts to map the overlap between different types of ISL. We classify firms according to whether they cooperate with universities, find public information very important, or, have patents that refer to scientific publications, or any combination of these ISL. While we might have expected some complementarity between the different types of ISL, the diversity we actually find at the firm level is striking. At the sector level there seems to be substantial correlation between different types of ISL as shown by Tables 1 and 2. But at the firm level we find considerable diversity. Only 5 firms combine all three types of ISL (and 4 of those firms are also involved in publishing). Interestingly, 7 firms that do not report any other ISL appear as firms with scientific NPRs in their patents; Out of these 7 firms 5 belong to the medium R\&D intensive industries. Only 45 firms use both cooperation in R\&D agreements with universities and public information as ISL. Out of these 45 firms only 5 report citation to science in their innovation outputs measured by patents. Similarly, the majority of firms with cooperative R\&D agreements with the university (60 out of 100) and firms that find public information very important (74 out of 121) do not have any other type of ISL. Very few firms (8) are directly involved in open science through publication, but more surprisingly, 5 of these firms are found in the medium low $R \& D$ intensive industries. These simple descriptive statistics - while based on a rather small sample - do corroborate the heterogeneity that exists in the ways to access scientific knowledge. At the same time our results reveal that each individual ISL measure might provide additional information about firms linking to science.

\section{Performance of Linkages to Science}

In this section we focus the analysis on whether and which type of ISL enables firms to achieve higher innovation and economic performance. Following the literature previously exposed, we expect that firms connected to science develop a comparative advantage in the production of innovation and notably, in the production of breakthrough innovation. ISL facilitate the 
absorbing and understanding of fundamental knowledge, allow firms to follow new discoveries, upgrade internal technological competences, and detect new opportunities for industrial innovation. All of these effects of ISL are expected to improve the productivity of applied research.

We present two levels of analysis. First, we relate ISL to the indicators of innovation and economic performance at the firm level reported in the CIS-3 data (section III.A). The key measure of innovation we will use is the percentage of innovations that are new to the market. The indicators of economic performance are the percentage of turnover due to innovations introduced in the past 2 years, and, the percentage of turnover due to new market introductions during those past 2 years. Second, we restrict our analysis to the 79 firms with patents and analyze the effect from ISL on the quality of patents, both at the level of the invention (i.c. the patent) and at the level of the patenting firms (section III.B).

\section{III.A. Science linkages and Economic Performance}

Table 3 displays the means for the R\&D intensity, the number of employees, sales, and the measures of innovation and economic performance broken down by ISL. The percentage of firms that declare innovation new to the market is reported in the last row. Not surprisingly, firms with at least one ISL (column 2) are larger in turnover, have more employees and have high R\&D intensity. These firms can more likely cover the sunk cost of becoming science linked. At the same time - corroborating the hypothesis advanced in the literature - firms with ISL have a higher percentage of sales from new or improved products (innovation turnover ratio) and a higher percentage of sales from innovative products that are new to the market (as opposed to new to the firm). Firms that have science linkages also show a higher frequency of innovations new to the market (47\% versus 38\%). When comparing different science linkages, 
firms declaring to cooperate with public institutions and also declaring the use of public sources of information as very important (column 5) have a high frequency of introducing innovations new to the market (44\%), but the group of firms having scientific references in their patents (column 7) appears as having the largest percentage of firms having introduced radical innovations (63\%). Firms with this ISL also display the highest innovation turnover ratio and turnover due to new market introductions, but these firms are also larger and have a significantly higher R\&D intensity. While firms with different ISL do display significant differences in size and R\&D intensity, the differences in innovation output is not significant. ${ }^{13}$

The correlation matrix in Table 4 offers additional insights on the correlation of ISL with respect to performance. Consistent with our finding about the diversity in ISL of firms, we find that having a link (column 1) has the highest correlation with the innovation turnover ratio, the new to market innovation turnover ratio and the new to market introduction indicator, while no one specific link seems to account for this positive effect.

Overall, we confirm the fact that ISL and firm innovation performance are positively related. At the same time, no single ISL seems to drive this result. Rather, firms can affect their (innovation) performance through engaging in various types of ISL, reinforcing the fact that we found substantive heterogeneity across firms in ISL.

\section{III.B. Science linkages and quality of patents}

We now turn to the analysis of the impact of industry science links on the quality of firm's inventions, as proxied by the quality of the firm's patents. As measure of patent quality we use the number of forward citations received. Past research has shown that the number of citations

\footnotetext{
${ }^{13}$ Small sample size is clearly an issue to obtain robust results.
} 
a patent receives is highly correlated with its technological importance and social value (Trajtenberg, 1990). Moreover, forward citations are correlated with the renewal rate of patents, the estimated economic value of inventions and patent opposition (Lanjouw and Schankerman, 1999; Harhoff et al, 1999; Hall et al, 2000).

We have also computed two additional quality indicators related to the technological impact of the patent based on forward citations: generality of the technology and geographical dispersion of the technology. A high generality score indicates that the patent had a broad technological impact where it influenced subsequent innovations in a broad set of technological fields (Hall et al, 2001). This indicator is build as a Herfindahl index (Jaffe et al, 1993; Hall et al, 2001): generality $=1-\sum_{i}^{n_{i}} s_{i j}{ }^{2}$, where $s_{i j}$ denotes the percentage of citations received by patent $\mathrm{j}$ that belong to patent class $i$, out of $n_{i}$ patent classes. ${ }^{14}$ If the patent receives all of its future citations from a single patent class, the index is equal to zero. A higher generality index implies a more technologically diverse the set of patents that cite the focal patent. The index of geographical dispersion is built in a similar way: geographic al dispersion $=1-\sum_{i}^{n_{i}} s_{i j}{ }^{2}$, where $s_{i j}$ denotes the percentage of citations received by patent $\mathrm{j}$ that come from country $i$, out of $n_{i}$ countries. The index is based on the country location of the inventors. A higher index means that future citations come from a more diverse set of countries, which relates to the notoriety of the technology.

We test the impact of industry science links on patent quality at two levels: the invention level and the firm level. For the invention level, we compare patent quality - number, technical and geographical scope of citations to the patent - of patents with scientific NPRs, as our measure of industry science link at the invention level, to the quality of patents without scientific NPRs.

\footnotetext{
${ }^{14}$ Patents are classified according to a system of technological patent classes (IPC-codes).
} 
For the firm level, we compare the quality of patents of firms with ISL (such as publishing, cooperating or scanning public knowledge) to the quality of patents of firms without ISL.

The analysis is performed on the 79 Flemish firms which hold granted patents from the European Patent Office with grant dates between 1995 and 2001. These 79 firms together account for 1186 patents. The forward citations to these patents - the number of citations received by the patent from future patents - are computed until 2003.

The breakdown of patent quality measures across the firms distinguished according to the different types of ISL they use, is reported in Table 5a. As expected, firms having at least one ISL to scientific communities report a higher likelihood of their patents being cited (dummy for having at least one forward citation), their patents appear more general in scope (are cited more across different technology classes) and have a higher geographical dispersion. However, the difference in means is significant (at 10\%) only for geographical dispersion and the frequency of being cited at least once (dummy for forward citation). Firms that cooperate or use public sources of information report on average 0,69 and 0,71 citations to their patents respectively and firms involved directly in science through own publication activity report an average 0,72 forward citations to their patents. These effects are only marginally significant. But they seem to confirm the superior performance in terms of patent quality from firms engaged in science linkages. No particular type of ISL seems to stand out in this relation.

Table 5b reports the comparison of patents with scientific references (NPRs) to patents without scientific references. Contrary to our expectations, we find that patents without NPRs are more likely to be cited (33\% versus 24\%) and have a higher mean of forward citations. But patents with NPRs are more general and more geographically dispersedly cited. Although the results 
are on a small sample and not robust ${ }^{15}$, they suggest that while patents with scientific NPRs protect more general technologies, more applied patents - patents without scientific NPRs actually capture the value for the firm. Patents citing a scientific publication appear to cover more fundamental knowledge and they are therefore more likely to be cited across a broad range of technology classes and across different countries. But this kind of patent is not different from the rest of patents based on the average count of citations received.

Finally, in Table 6 we combine the invention and the firm level of analysis. Controlling for firm level ISL, we compare the quality of patents with and without NPRs. In the first panel we consider only firms with scientific publications and look at the quality of patents with and without scientific NPRs (cols (1) and (2)). We confirm the results from Table 5b that patents with scientific NPRs are more general and their citations are more geographically dispersed, but these patents are less likely to be cited. However, and more interestingly, comparing the forward citations of patents without NPRs of these firms that publish with patents without scientific NPRs of other firms that have no publications (cols (2) and (4)), we find that the patents of publishing firms are more likely to be cited and receive more citations $(0,36$ versus $0,27)$ and $(0,72$ versus 0,55$)$ respectively. Our interpretation is that firms with scientific publications not only are more likely to have patents with scientific NPRs, but also have higher quality applied patents (patents without scientific NPRs) thanks to their more fundamental knowledge of the technology. This result is confirmed in the panels below for firms that cooperate in R\&D with public research institutions, or, for firms that consider public sources of information very important. We conclude that controlling for the firm level science links when evaluating patent quality is crucial to pick up the innovation performance effect of these science links - the higher new to market innovation content of these innovations. Patents from firms

\footnotetext{
${ }^{15}$ Only for generality and the likelihood of receiving a forward citation, these differences are significant, but only at the $10 \%$ level.
} 
engaged in ISL will be more valuable and are more likely to lead to innovations that are new to the market.

\section{Conclusions}

This paper examines the diversity of the types of links to science and their association to innovation performance for a sample of Flemish firms. We identify different ways to access scientific knowledge, using information from the Eurostat, Community Innovation Survey, and add additional measures on the use of science by firms by analyzing publication data and citations to science in these firms’ patents.

We confirm previous findings in the literature that firms with science linkages seem to enjoy a superior innovation performance. However, contrary to our expectation we find that different types of ISL are not complementary. While firms engage in different forms of ISL, the positive effect of these links cannot be related to a particular type of linkage.

Furthermore, the causality does not necessarily run as expected. Patents that directly cite science are actually less likely to be cited, presumably because of their more basic nature. But if cited, these citations are more likely to come from a broader set of technologies and geographies, consistent with their more basic nature. Patents from firms that are actively engaged in ISL at the firm level through cooperative R\&D agreements, publishing or scanning public information sources are more highly cited, especially those that $d o$ not refer to science directly. We speculate that firms with active ISL develop more basic technologies and have a better understanding of the fundamental technologies. As a result their regular patents (i.e. not directly linked to science) are also more valuable. 
While our sample of firms is limited, we can nevertheless provide some policy suggestions.

Our results indicate that several indicators need to be tracked to obtain a representative picture of the ISL activity of a firm, an industry and a country. In addition, to bring out the true effect of these links, firm and invention level indicators need to be interacted. Furthermore, our results indicate that further research is needed to understand the process of how the link with science affects the productivity of applied research internal to the firm. Understanding this process would open the door to develop more relevant measures related to the effect of science on innovation at the micro-level.

\section{REFERENCES}

Adams, J. D. (1990). Fundamental stocks of knowledge and productivity growth, Journal of Political Economy, 98: 673-702.

Adams, J., E. Chiang and J. Jensen (2000), The influence of federal laboratory R\&D on industrial research, NBER working paper 7612 .

Alcacer, J. and Gittelman, M (2006) How do I know what you know? Patent examiners and the generation of patent citations, Review of Economics and Statistics, 88(4):774-779.

Arora, A., and Gambardella, A. (1990). Complementarity and External linkages: the strategies of the large firms in Biotechnology, Journal of Industrial Economics, 38: 361-379.

Arundel, A. and Geuna, A. (2004).Proximity and the Use of Public Science by Innovative European Firms', Economics of Innovation and New Technology, 13: 559-580, 2004.

Audretsch, D.B. and Stephan, RE. (1996) Company-scientist locational links: the case of biotechnology, American Economic Review, 86: 641-652.

Belderbos, R. Carree, M, and Lokshin, B. (2005) Cooperative R\&D and Firm Performance. Research Policy 33 : 1477-1492.

Branstetter, L. (2004), Exploring the Link between Academic Science and Industrial innovation, unpublished working paper.

Cassiman, B., Di Guardo, M.C. and G. Valentini (2009) "Collaboration and Competition in the Organization of R\&D Projects," with Chiara Di Guardo and Giovanni Valentini, forthcoming, Long Range Planning.

Cassiman, B., Perez-Castrillo, D. and R. Veugelers (2001) Endogeneizing know-how flows through the nature of $\mathrm{R} \& \mathrm{D}$ investments, The International Journal of Industrial Organization, 20 (6), p. 775-799.

Cassiman, B., Veugelers, R. and M.P. Zuniga, (2008) In Search of Performance Effects of (in)Direct Industry - Science Links, Industrial and Corporate Change, 17(4), p. 611-646.

Cockburn, I. and Henderson, R. (1998). Absorptive capacity, coauthoring behavior, and the organiwation of research in drug discovery. The Journal of Industrial Economics, 46 (2): 157-182.

Cockburn, I., Henderson, R. and Stern, S. (1999). The Diffusion of Science-Driven Drug Discovery: Organizational Change in Pharmaceutical Research, NBER document de travail no. 7359, National Bureau of Economic Research, Inc. 
Cohen W. M, Levinthal, D. A. (1989). Innovation and learning: the two faces of R\&D. The Economic Journal 99: 569-596.

Cohen W. M, Levinthal D. A. (1990). Absorptive capacity, a new perspective of learning and innovation. Administrative Science Quarterly 35: 128-152

Cohen, W. M.; Nelson, R.; Walsh, R. John P. (2002). Links and Impacts: The Influence of Public Research on Industrial R\&D, Management Science, 48 (1): 1-23

Darby, M. R., L.G. Zucker (2001). Change or die: The adoption of biotechnology in the Japanese and U.S. pharmaceutical industries. Res. Tech. Innovation, Management, Policy 7: 85-125.

Darby, M. and L.G. Zucker (2005) Grilichesian breakthrougus: Inventions of methods of invention and firm entry in nanotechnology, Annales d'Economie et Statistique, forthcoming.

Evenson, R.E., and Kislev, Y. A (1976). Stochastic Model of Applied Research, Journal of Political Economy 84: 265-281.

Griliches, Z. (1979). Isues in Assessing th contribution of research an development to productivity growth, Bell Journal of Economics, 10 (1): 92-116.

Fleming, L., and Sorenson, O. (2004) Science as a map in technological search. Strategic Management Journal, 25: 909-9280.

Gambardella, A. (1992). Competitive advantages from in-house scientific research: the U.S. pharmaceutical industry in the 1980s. Research Policy, 21: 391-407.

Gambardella, A. (1994). The changing technology of technical change: General and abstract knowledge and the division of innovative labor. Research Policy, 23: 523-532.

Hall, B. H, Jaffe, A. D, Trajtenberg M. (2000). Market Value and Patent Citations: A First Look, Economics Department Working Paper E00-277, University of California

Hall, B.H., Link, A. and J.T. Scott (2001), Universities as research partners, NBER working paper 7643.

Harhoff, D. and Narin, F., F. M. Scherer and K. Vopel (1999). Citation Frequency and The Value of Patented Inventions, The Review of Economics and Statistics, MIT Press, vol. 81(3): 511-515

Henderson; R. and Cockburn, I. (1996). Scale, scope and spillovers: the determinants of research productivity in drug discovery, RAND Journal of Economics, 27 (1): 401-424.

Henderson, R., A. Jaffe, M. Trajtenberg (1998), Universities as a source of commercial technology: A detailed analysis of University patenting, 1965-1988. Review of Economics and Statistics, 65: 119-127.

Hicks, D., Breitzman, T., Olivastro, D., Hamilton, K. (2001). The changing composition of innovative activity in the US a portrait based on patent analysis. Research Policy, 30: 681703.

Jaffe, A. B., Trajtenberg, M. Henderson, R. (1993). Geographic Localization of knowledge spillovers as evidenced by patent citations. Quaterly Journal of Economics 108, 577-598.

Jensen, R. and Thursby, M. (2001). Proofs and Prototypes for Sale: The Licensing of University Inventions, American Economic Review, 91(1) : 240-59.

Kamien, M. and I. Zang (2000) Meet me halfway: research joint ventures and absorptive capacity, International Journal of Industrial Organisation, 18(7).

Kim, J., Sangjoon, L. J. and Marschke, G. (2005). The influence of university research on industrial innovation NBER working Paper 11447, June 2005.

Lanjouw, J. O., Schankerman, M. (1999). The Quality of Ideas: Measuring Innovation with Multiple Indicators. NBER, Boston, MA.

Liebeskind J. P., Oliver A. L, Zucker L, Brewer M. (1996). Social networks, learning, and flexibility: sourcing scientific knowledge in new biotechnology firms. Organization Science 7(4): 428-442 
Mansfield, E. (1991). Academic Research and Industrial Innovation. Research Policy, 20(1):112.

Mansfield, E., (1995), Academic Research Underlying Industrial Innovations: Sources, Characteristics, and Financing, The Review of Economics and Statistics, 77: 55-65.

Narin, F., Hamilton, K., Olivastro, D., (1997). The increasing linkage between US technology and public science. Research Policy 26: 317-330.

OECD (2001). OECD Science, Technology and Industry Scoreboard. Organization for Economic Co-operation and Development.

Stern, S. (1999). Do Scientists Pay to Be Scientists?, NBER Working Papers 7410, National Bureau of Economic Research, Inc.

Thursby J. G. and M.C. Thursby, (2002) Who is selling the Ivory Tower? Sources of growth in university licensing. Management Science, 48: 90-104.

Trajtenberg, M. (1990), A penny for your quotes: patent citations and the value of innovation RAND Journal of Economics, 21 (1): 172-187.

Van Looy, B., Magerman, T. and Debackere, K. (2004). Developing technology in the vicinity of science: An examination of the relationship between science intensity and technological productivity within the field of biotechnology. KU Leuven, mimeo.

Veugelers, R. and Cassiman, B. (2005). R\&D Cooperation between firms and universities: Some empirical evidence from Belgian manufacturing, International Journal of Industrial Organization, 23 (5-6), p. 355-379.

Zucker, L., M. Darby, and M. Brewer (1998), Intellectual Capital and the Birth of U.S. Biotechnology Enterprises, American Economic Review, 88: 290-306.

Zucker, L.G. and Darby, M.R., (2001). Capturing Technological Opportunity via Japan's Star Scientists: Evidence from Japanese Firms' Biotech Patents and Products, The Journal of Technology Transfer, Springer, 26(1-2): 37-58.

Zucker, L.G.; Darby M.R. and Armstrong, J.S. (2002). Commercializing Knowledge: University Science, Knowledge Capture, and Firm Performance in Biotechnology, Management Science, 48(1), 2002. 
Figure 1: Overlap between Types of ISL

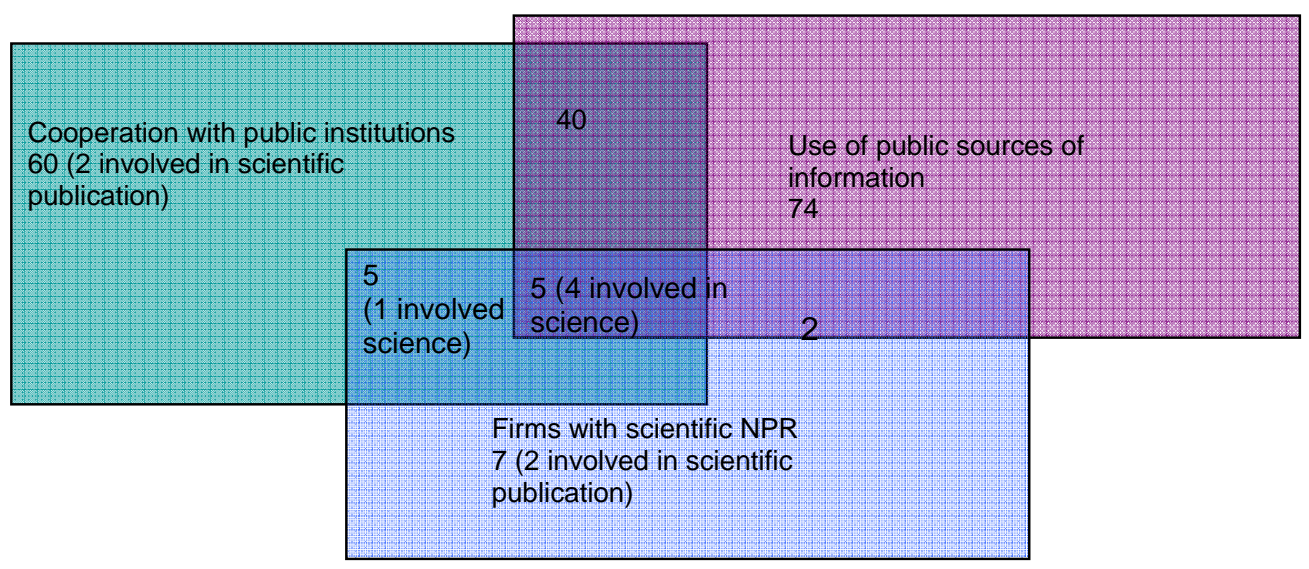

Firms without linkage to science

649 (1 involved in scientific publication) 
Table 1: Distribution of Firms across Industries and Type of ISL

\begin{tabular}{|c|c|c|c|c|c|c|c|c|c|c|c|c|c|c|c|}
\hline Industry & $\begin{array}{l}\text { Number } \\
\text { of Firms }\end{array}$ & $\begin{array}{l}\text { Firms } \\
\text { without } \\
\text { links to } \\
\text { science } \\
\end{array}$ & $\%$ & $\begin{array}{l}\text { Cooperation } \\
\text { with public } \\
\text { institutes=1 }\end{array}$ & $\%$ & $\begin{array}{l}\text { Use of } \\
\text { public } \\
\text { informati } \\
\text { on=1 }\end{array}$ & $\%$ & $\begin{array}{l}\text { Cooperation } \\
\text { and Use of } \\
\text { public } \\
\text { information }\end{array}$ & $\%$ & $\begin{array}{l}\text { Firms } \\
\text { patents }\end{array}$ & with $\%$ & $\begin{array}{l}\text { Scientific } \\
\text { NPR } \\
\text { patents=1 }\end{array}$ & $\%$ & $\begin{array}{ll}\text { Firms } & \text { with } \\
\text { publications }\end{array}$ & $\%$ \\
\hline Food and tobbaco & 74 & 59 & $79,73 \%$ & 9 & $12,16 \%$ & 8 & $10,81 \%$ & 2 & $2,70 \%$ & 3 & $4,05 \%$ & 0 & $0,00 \%$ & 0 & $0,00 \%$ \\
\hline Textiles & 68 & 55 & $80,88 \%$ & 9 & $13,24 \%$ & 8 & $11,76 \%$ & 4 & $5,88 \%$ & 2 & $2,94 \%$ & 0 & $0,00 \%$ & 0 & $0,00 \%$ \\
\hline Wood, printing, publishing & 82 & 69 & $84,15 \%$ & 3 & $3,66 \%$ & 9 & $10,98 \%$ & 1 & $1,22 \%$ & 4 & $4,88 \%$ & 1 & $1,22 \%$ & 0 & $0,00 \%$ \\
\hline Chemicals, coke, petroleum & 85 & 54 & $63,53 \%$ & 14 & $16,47 \%$ & 16 & $18,82 \%$ & 7 & $8,24 \%$ & 10 & $11,76 \%$ & 5 & $5,88 \%$ & 3 & $3,53 \%$ \\
\hline Rubber and plastic & 84 & 63 & $75,00 \%$ & 13 & $15,48 \%$ & 14 & $16,67 \%$ & 7 & $8,33 \%$ & 10 & $11,90 \%$ & 1 & $1,19 \%$ & 1 & $1,19 \%$ \\
\hline Glass, ceramic & 39 & 31 & $79,49 \%$ & 3 & $7,69 \%$ & 4 & $10,26 \%$ & 1 & $2,56 \%$ & 2 & $5,13 \%$ & 1 & $2,56 \%$ & 1 & $2,56 \%$ \\
\hline Metals, metallurgy & 121 & 91 & $75,21 \%$ & 14 & $11,57 \%$ & 19 & $15,70 \%$ & 7 & $5,79 \%$ & 15 & $12,40 \%$ & 3 & $2,48 \%$ & 3 & $2,48 \%$ \\
\hline Machinery, equipment & 114 & 85 & $74,56 \%$ & 14 & $12,28 \%$ & 16 & $14,04 \%$ & 6 & $5,26 \%$ & 16 & $14,04 \%$ & 4 & $3,51 \%$ & 0 & $0,00 \%$ \\
\hline Electronics & 56 & 33 & $58,93 \%$ & 14 & $25,00 \%$ & 11 & $19,64 \%$ & 4 & $7,14 \%$ & 9 & $16,07 \%$ & 2 & $3,57 \%$ & 0 & $0,00 \%$ \\
\hline Medical and precision instruments & 18 & 8 & $44,44 \%$ & 4 & $22,22 \%$ & 8 & $44,44 \%$ & 4 & $22,22 \%$ & 4 & $22,22 \%$ & 2 & $11,11 \%$ & 0 & $0,00 \%$ \\
\hline Vehicles & 62 & 48 & $77,42 \%$ & 10 & $16,13 \%$ & 5 & $8,06 \%$ & 1 & $1,61 \%$ & 3 & $4,84 \%$ & 0 & $0,00 \%$ & 0 & $0,00 \%$ \\
\hline Furniture & 39 & 34 & $87,18 \%$ & 3 & $7,69 \%$ & 3 & $7,69 \%$ & 1 & $2,56 \%$ & 1 & $2,56 \%$ & 0 & $0,00 \%$ & 0 & $0,00 \%$ \\
\hline Total & 842 & 630 & $74,82 \%$ & 110 & $13,06 \%$ & 121 & $14,37 \%$ & 45 & $5,34 \%$ & 79 & $9,38 \%$ & 19 & $2,26 \%$ & 8 & $0,95 \%$ \\
\hline
\end{tabular}

Use of Public sources: firms thablic Institutes: firms that declare cooperating with universities and/or public research institutes (either national and international) as the only mean of accessing scientific knowledge. Only private non profit research institutes and from professional conferences, meeting and journals.

Table 2: Distribution of Firms across groups of Industries and Type of ISL

\begin{tabular}{|c|c|c|c|c|c|c|c|c|c|c|c|c|c|c|c|}
\hline Industry Group & $\begin{array}{l}\text { Number } \\
\text { of Firms }\end{array}$ & $\begin{array}{l}\text { Firms } \\
\text { without } \\
\text { links to } \\
\text { science } \\
\end{array}$ & $\%$ & $\begin{array}{l}\text { Cooperation } \\
\text { with public } \\
\text { institutes }=1\end{array}$ & $\%$ & $\begin{array}{l}\text { Use of } \\
\text { public } \\
\text { informati } \\
\text { on=1 }\end{array}$ & $\%$ & $\begin{array}{l}\text { Cooperation } \\
\text { and Use } \\
\text { public } \\
\text { information }\end{array}$ & of $\%$ & $\begin{array}{l}\text { Firms with } \\
\text { patents }\end{array}$ & $\%$ & $\mid \begin{array}{l}\text { Scientific } \\
\text { NPR } \\
\text { patents=1 }\end{array}$ & $\%$ & $\begin{array}{l}\text { Firms with } \\
\text { publications }\end{array}$ & $\%$ \\
\hline Low R\&D Intensive Industries & 263 & 217 & $82,51 \%$ & 24 & $9,13 \%$ & 28 & $10,65 \%$ & 8 & $3,04 \%$ & 10 & $3,80 \%$ & 1 & $0,38 \%$ & 0 & $0,00 \%$ \\
\hline Medium Low R\&D Intensive Industr & 257 & 197 & $76,65 \%$ & 31 & $12,06 \%$ & 38 & $14,79 \%$ & 16 & $6,23 \%$ & 28 & $10,89 \%$ & 5 & $1,95 \%$ & 5 & $1,95 \%$ \\
\hline Medium High R\&D Intensive Indust & 271 & 194 & $71,59 \%$ & 42 & $15,50 \%$ & 38 & $14,02 \%$ & 13 & $4,80 \%$ & 31 & $11,44 \%$ & 7 & $2,58 \%$ & 2 & $0,74 \%$ \\
\hline High R\&D Intensive Industries & 51 & 22 & $43,14 \%$ & 13 & $25,49 \%$ & 17 & $33,33 \%$ & 8 & $15,69 \%$ & 10 & $19,61 \%$ & 6 & $11,76 \%$ & 1 & $1,96 \%$ \\
\hline Total & 842 & 630 & $74,82 \%$ & 110 & $13,06 \%$ & 121 & $14,37 \%$ & 45 & $5,34 \%$ & 79 & $45,74 \%$ & 19 & $2,26 \%$ & 8 & $0,95 \%$ \\
\hline
\end{tabular}

Note: We follow criteria used by the OECD (OECD, 2002). High Technology groups the two classes : Medium-high-technology industries (Scientific instruments, Motor vehicles, Electrical machines excl. commun. equip., Chemicals excl. drugs, Other transport, and Non-electrical

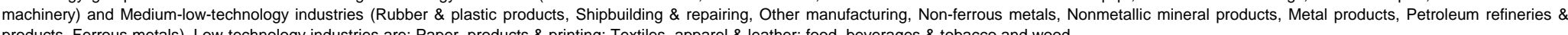


Table 3: Types of ISL and Firm Performance

\begin{tabular}{|c|c|c|c|c|c|c|c|}
\hline Variable & $\begin{array}{l}\text { No linkage to } \\
\text { science }\end{array}$ & $\mid \begin{array}{lr}\text { At least } & \text { one } \\
\text { linkage } & \text { to } \\
\text { science } & \\
\end{array}$ & $\begin{array}{l}\text { Cooperation } \\
\text { with public } \\
\text { institutes }\end{array}$ & \begin{tabular}{|l|} 
Use of public \\
information
\end{tabular} & $\begin{array}{l}\text { Cooperation and } \\
\text { Use of public } \\
\text { information }\end{array}$ & $=\begin{array}{l}\text { Scientific } \\
\text { References in } \\
\text { patents }\end{array}$ & $\begin{array}{l}\text { Firms with } \\
\text { publications }\end{array}$ \\
\hline & 1 & 2 & 3 & 4 & 5 & 6 & 7 \\
\hline R\&D Intensity (per employee) & 76.49672 & $210.15^{\star \star \star}$ & $258.46^{\star \star \star}$ & $191.804^{\star \star}$ & $290.29^{\star \star}$ & $540.31^{\star *}$ & 510.0542 \\
\hline Employees & 122.0722 & $440.373^{\star \star *}$ & $637,69 * \star \star$ & 259,84 & $477,04^{\star *}$ & $1739,37^{\star \star \star}$ & $2309.125^{\star *}$ \\
\hline Turnover sales & 1117340,00 & $5649051^{\star \star \star}$ & $8279243^{\star \star \star}$ & $3477041^{*}$ & $7210230 * \star$ & $22100000^{\star \star}$ & $3.12 \mathrm{e}+07^{\star \star}$ \\
\hline Turnover due to Innovation & .1002181 & $.2010638^{\star \star \star}$ & $0,1851818^{\star \star}$ & $0,194^{\star \star \star}$ & 0,15 & $0,2452632^{\star *}$ & .1125 \\
\hline Turnover due to new market introduction & .0295483 & $.0843085^{\star \star \star}$ & $0,0959091^{\star \star \star}$ & $0,0703306^{* *}$ & $0,082^{*}$ & $0,1336842^{*}$ & .04125 \\
\hline New Market Introductions & 0.38 & 0.47 & 0.42 & 0,36 & 0,44 & 0,63 & 0,57 \\
\hline
\end{tabular}

Table 4: Correlation matrix

\begin{tabular}{|c|c|c|c|c|c|c|c|c|c|c|c|c|c|}
\hline & & 1 & 2 & 3 & 4 & 5 & 6 & 7 & 8 & 9 & 10 & 11 & 12 \\
\hline At least one link to science & 1 & 1.0000 & & & & & & & & & & & \\
\hline Cooperation with public institutes & 2 & $0.7109^{*}$ & 1.0000 & & & & & & & & & & \\
\hline Use of public information & 3 & $0.7512^{*}$ & $0.2933^{\star}$ & 1.0000 & & & & & & & & & \\
\hline Coperation and use of public info. & 4 & $0.4357^{\star}$ & $0.6130^{\star}$ & $0.5800^{*}$ & 1.0000 & & & & & & & & \\
\hline Scientific references in patents & 5 & $0.2786^{*}$ & $0.1784^{\star}$ & $0.0973^{*}$ & $0.1417^{*}$ & 1.0000 & & & & & & & \\
\hline Firms with publications & 6 & $0.1631^{*}$ & $0.1653^{\star}$ & $0.0891^{*}$ & $0.1807^{*}$ & $0.5286^{*}$ & 1.0000 & & & & & & \\
\hline R\&D intensity (employee) & 7 & 0.0696 & 0.0673 & 0.0410 & 0.0572 & $0.1520^{*}$ & 0.0906 & 1.0000 & & & & & \\
\hline Employees & 8 & $0.2458^{*}$ & $0.3190^{*}$ & 0.0484 & $0.1250^{*}$ & $0.4391^{*}$ & $0.3638^{\star}$ & $0.0977^{*}$ & 1.0000 & & & & \\
\hline New Market Introduction & 9 & $0.2228^{*}$ & $0.1963^{\star}$ & $0.1527^{*}$ & $0.1356^{*}$ & $0.1564^{*}$ & 0.0593 & 0.0714 & $0.1133^{\star}$ & 1.0000 & & & \\
\hline Turnover sales & 10 & $0.2303^{*}$ & $0.2943^{\star}$ & 0.0675 & $0.1490^{*}$ & $0.3746^{*}$ & $0.3299^{*}$ & $0.1295^{*}$ & $0.7913^{\star}$ & $0.1080^{*}$ & 1.0000 & & \\
\hline Turnover due to Innovation & 11 & $0.2001^{*}$ & $0.1170^{\star}$ & $0.1424^{*}$ & 0.0259 & $0.0898^{*}$ & -0.0029 & 0.0532 & $0.1553^{\star}$ & $0.2769^{*}$ & 0.0603 & 1.0000 & \\
\hline Turnover due to new market introductio & 12 & $0.1808^{*}$ & $0.1712^{\star}$ & $0.0957^{*}$ & $0.0793^{*}$ & $0.1138^{\star}$ & -0.0042 & $0.1100^{*}$ & 0.0584 & $0.5836^{\star}$ & 0.0451 & $0.5004^{*}$ & 1.0000 \\
\hline
\end{tabular}

Note: * significant correlation at $5 \%$ and better. 
Table 5a: Patent quality and Types of ISL: the firm level

\begin{tabular}{|c|c|c|c|c|c|c|c|}
\hline & $\begin{array}{l}\text { All } \\
1 \\
1\end{array}$ & No link & $\begin{array}{l}\text { At least } \\
\text { one link } \\
2\end{array}$ & $\begin{array}{c}\text { Cooperation with } \\
\text { Public } \\
\text { Institutions } \\
3\end{array}$ & $\begin{array}{c}\text { Use of } \\
\text { Public } \\
\text { Sources } \\
4\end{array}$ & $\begin{array}{l}\text { Cooperation and } \\
\text { use of public } \\
\text { information } \\
5\end{array}$ & $\begin{array}{c}\text { Scientific } \\
\text { firm } \\
\text { (publication } \\
6\end{array}$ \\
\hline Dummy forward citation ${ }^{a}$ & 0,33 & 0,30 & $0,33^{*}$ & $0.34^{*}$ & $0.34^{*}$ & $0.34^{*}$ & $0.35^{\star \star}$ \\
\hline Forward Citation ${ }^{\mathrm{b}}$ & 0,67 & 0,70 & 0,67 & $0.69^{*}$ & $0.71^{*}$ & 0,65 & $0.72^{*}$ \\
\hline generality $^{b}$ & 0,10 & 0,09 & 0,10 & 0,10 & 0,10 & 0,09 & 0,10 \\
\hline geographical impact $^{\mathrm{b}}$ & 0,22 & 0,14 & $0.188^{\star}$ & 0,19 & 0,19 & 0,20 & $0.194^{*}$ \\
\hline
\end{tabular}

Note: ${ }^{*}$ significance at $10 \%,{ }^{* \star}$ at $5 \%$. At least one link: firms that cooperate or use public information or are involved in scientific publications. The forward citations contitute the number of citations received from other EPO patents. The measures of generality and geographical impact as well as the tests for the comparison of means (and proportions) are calculated only on the patents having received forward citations. a: Pearson Chi-square test on the significance of the relationship between the two groups (categorical variables); b: t-test on the significance of difference in

Table 5b: Patent quality and NPR: the invention(patent) level

\begin{tabular}{|lcccc|}
\hline & All & $\begin{array}{l}\text { Patents } \\
\text { with NPR }\end{array}$ & $\begin{array}{l}\text { Patents } \\
\text { without } \\
\text { NPR }\end{array}$ & 7 vs 8 \\
\hline Dummy forward citation $^{\mathrm{a}}$ & 1 & 7 & 8 & 9 \\
\hline Forward Citation $^{\mathrm{b}}$ & 0,33 & 0,24 & 0,33 & $4.26^{*}$ \\
generality $^{\mathrm{b}}$ & 0,67 & 0,64 & 0,67 & 0,193 \\
geographical impact $^{\mathrm{b}}$ & 0,10 & 0,17 & 0,08 & $-2.14^{\star}$ \\
\hline
\end{tabular}

Note: * significance at $10 \%,{ }^{*}$ at $5 \%$. The forward citations contitute the number of

citations received from other EPO patents. The measures of generality and

geographical impact as well as the tests for the comparison of means (and

proportions) are calculated only on the patents having received forward citations. a: 
Table 6: Effects of NPR and other Types of ISL on Patent Quality

\begin{tabular}{|c|c|c|c|c|}
\hline & \multicolumn{2}{|c|}{ Firms with scientific Publications } & \multicolumn{2}{|c|}{ Firms without scientific Publications } \\
\hline \multirow[t]{2}{*}{ Patent Indicators } & With NPR & Without NPR & With NPR & Without NPR \\
\hline & 1 & 2 & 3 & 4 \\
\hline Forward dummy $^{a}$ & 0,25 & $0.36^{\star *}$ & 0,22 & 0,27 \\
\hline Forward citation $^{\mathrm{b}}$ & 0,71 & $0.72^{*}$ & 0,407 & 0,55 \\
\hline generality $^{\mathrm{b}}$ & 0,16 & 0,09 & 0,24 & 0,084 \\
\hline \multirow[t]{2}{*}{ geographical impact ${ }^{\text {b }}$} & 0,21 & $0.19 *$ & 0,32 & 0,14 \\
\hline & \multicolumn{2}{|c|}{$\begin{array}{l}\text { Firms that cooperate with public } \\
\text { institutions }\end{array}$} & \multicolumn{2}{|c|}{$\begin{array}{c}\text { Firms that do not cooperate with public } \\
\text { institutions }\end{array}$} \\
\hline \multirow[t]{2}{*}{ Patent Indicators } & With NPR & Without NPR & With NPR & Without NPR \\
\hline & 1 & 2 & 3 & 4 \\
\hline Forward dummy $^{a}$ & $0.27^{*}$ & $0.35^{*}$ & 0,058 & 0,27 \\
\hline Forward citation ${ }^{\text {b }}$ & 0.73 & 0,69 & 0,11 & 0,57 \\
\hline generality $^{b}$ & $0.16^{\mathrm{c}}$ & 0,091 & 0,5 & 0,072 \\
\hline \multirow[t]{2}{*}{ geographical impact $^{\text {b }}$} & 0,23 & 0,18 & 0,22 & 0,15 \\
\hline & \multicolumn{2}{|c|}{$\begin{array}{c}\text { Firms that consider public } \\
\text { sources of information as very } \\
\text { important }\end{array}$} & \multicolumn{2}{|c|}{$\begin{array}{l}\text { Firms that do not consider public } \\
\text { sources of information as very } \\
\text { important }\end{array}$} \\
\hline \multirow[t]{2}{*}{ Patent Indicators } & With NPR & Without NPR & With NPR & Without NPR \\
\hline & 1 & 2 & 3 & 4 \\
\hline Forward dummy $^{a}$ & 0,25 & $0.355^{\star}$ & 0,22 & 0,29 \\
\hline Forward citation $^{b}$ & 0,71 & $0.71^{*}$ & 0,407 & 0,57 \\
\hline generality $^{\mathrm{b}}$ & 0,16 & 0,09 & 0,24 & 0,08 \\
\hline geographical impact ${ }^{\mathrm{b}}$ & 0,21 & $0.189 *$ & 0,32 & 0,15 \\
\hline
\end{tabular}




\section{Conomics}

The Open-Access, Open-Assessment E-Journal

\section{Please note:}

You are most sincerely encouraged to participate in the open assessment of this discussion paper. You can do so by posting your comments.

Please go to:

http://www.economics-ejournal.org/economics/discussionpapers/2009-30

The Editor 